Canadian

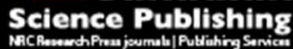

Canadian Geotechnical Journal Revue canadienne de géotechnique

\title{
Rheological Properties of Loose Sands Subjected to Upward Flow
}

\begin{tabular}{|r|l|}
\hline Journal: & Canadian Geotechnical Journal \\
\hline Manuscript ID & cgj-2016-0171.R2 \\
\hline Manuscript Type: & Article \\
\hline Date Submitted by the Author: & 06-Oct-2016 \\
\hline Complete List of Authors: & $\begin{array}{l}\text { Kang, Hyo-Sub; Pukyong National University } \\
\text { Kim, Yun-Tae; Pukyong National University }\end{array}$ \\
\hline Keyword: & $\begin{array}{l}\text { debris flow rheology, vane-measured rheometer, loose sands, viscosity, } \\
\text { yield stress }\end{array}$ \\
\hline \multicolumn{2}{|l}{} \\
\hline
\end{tabular}

SCHOLARONE ${ }^{\text {IM }}$

Manuscripts 


\title{
Rheological Properties of Loose Sands Subjected to Upward Flow
}

\author{
Hyo-sub Kang ${ }^{*} \cdot$ Yun-tae Kim ${ }^{* *}$
}

\begin{abstract}
The objective of this study was to investigate the rheological properties of loose sands subjected to upward flow by using a vane-type rheometer that controlled upward flow in the loose sand specimens. Various hydraulic gradients (i.e., $\mathrm{i}=0-2.0$ ) were applied to loose sands. The rheological properties of the loose sands, such as yield stress and viscosity, were determined based on the Bingham and Herschel-Bulkley models. The experimental results showed that the flow behavior of loose sand samples exhibited a shear thickening when the Herschel-Bulkley model was applied (i.e., $n>1$ ) and exhibited a Bingham-like within a limited shear rate range (i.e., 1 30 1/s). The latter is clearly shown for a relatively high shear rate. As the hydraulic gradient was increased, the flow characteristics are close to the Bingham fluid. Yield stress showed a tendency to decrease linearly as hydraulic gradient was increased. However, the viscosity of the loose sands maintained a constant value irrespective of hydraulic gradient. The test results indicated that the pore fluid pressure resulting from upward flow in a soil sample affects yield stress, which contributes to the initiation of debris flow mobilization. As a result, it was possible to estimate the rheological properties of soil at the condition of liquefaction (critical hydraulic gradient), or initial occurrence of debris flow.
\end{abstract}

Key Words: Debris flow rheology, vane-measured rheometer, loose sands, viscosity, yield stress 
*Postdoctoral researcher, Department of Ocean Engineering, Pukyong National University

(E-mail:monkle0@hanamail.net).

**Corresponding Author. Member. Professor, Department of Ocean Engineering, Pukyong National University

(Tel : +82-51-629-6587, Fax : +82-51-629-6580, E-mail: yuntkim@pknu.ac.kr). 


\section{Introduction}

Debris flows usually occur during heavy rainfall, when a slide may develop into a debris flow. They may reach long distances and high velocities, which causes serious potential geological hazards that can affect vast areas of inhabited regions.

Debris flow mobility is associated with the run-out distance and velocity of fluidized soil (Imran et al. 2001; Locat et al. 2004), and such characteristics of debris flow behavior depend strongly on internal factors (e.g., rheological properties, hydraulic-mechanical properties, and soil properties) and external factors (e.g., topographic characteristics). Debris flow mobility can be interpreted according to rheological properties, including yield stress and viscosity, which are major parameters for determining characteristics of debris flow behavior.

In general, the rheometer has been used to measure rheological properties of fluidized materials such as asphalt, cement, paint, ink, and food (Barnes et al. 1989). The rheometer has also been used with fine-grained soils (Jeong et al. 2010; Locat and Demers 1988; Malet et al. 2005; O’Brien and Julien 1988) and granular materials (Scotto di Santolo et al. 2010; Ilstad et al. 2004; Schatzmann et al. 2003) in research on the rheological properties of debris flows. Most studies have focused only on the characteristics of rheological properties, which depend on the water content, liquidity index, and volumetric water content of soil (Jeong et al. 2010; Locat and Demers 1988; O'Brien and Julien 1988). Due to the limitations of commercial testing equipment, the grain size range of soils tested is limited. It is very difficult to investigate the rheological properties of coarse-grained soils including a coarse fraction using the available commercial equipment.

The interaction between porous soil and pore fluid is important for understanding the dynamic characteristics of debris flows. Pore fluid pressure in a soil reduces shear strength, and this is a major cause for large run-out distance of debris flow. Field observations and laboratory experiments show that a debris flow mobilizes upon a condition of liquefaction of the sliding mass due to high pore fluid pressure (Iverson et al. 1997; Sassa 2000; Wang and Sassa 2003). Thus, pore fluid pressure is a key element in debris flow initiation and flow mobility, and it is necessary to investigate the rheological 
properties of debris flow material using the condition of liquefaction for debris flow hazard assessment.

The objective of this study was to investigate the characteristics of the rheological properties of loose sands, which are subjected to upward flows, using a large vane-type rheometer. Hydraulic gradients of upward flow in loose sand specimens range from 0 to 2 . As a result, it is possible to evaluate the rheological properties of loose sands under the condition of liquefaction. These rheological properties correspond to the initial properties of debris flow occurrence. The measured rheological properties under the condition of debris flow mobilization provide more accurate results with respect to the mobility of debris flows.

\section{Debris flow generation}

Debris flows can be classified into two forms, hill-slope debris flow and channelized debris flow, based on the topographic and geological characteristics of their locations (Winter et al. 2005). Channelized debris flow occurs when debris flows into and accumulates in a valley due to shallow failure of the slope around the valley. Fig. 1 shows a schematic illustration of the process of initial occurrence of channelized debris flow. Infiltration and surface runoff occur at the ground surface during heavy rainfall. Rainfall infiltration into the slope contributes to an increase in pore water pressure and results in a decrease in the shear strength of soils. The most common slope failure in weathered soil deposits is rainfall-induced shallow landsliding followed by flow of the disturbed mass, which most often occurs after periods of heavy rainfall (Kim et al. 2002).

Soil movement along the sliding surface causes loose deposits to contract and thus generates pore water pressure in the loose deposits. The generation of high pore water pressure causes liquefaction of the loose deposits, which then develop into mobilized debris flow. Similar mechanisms have been observed in field and laboratory tests (Gabet and Mudd 2005; Wang and Sassa 2002).

The loose ground can be liquefied by the reactions to upward flow from the left and the right sides of the valley, pore fluid flow in the soils, or uplift infiltration pressure flowing out from fractured 
bedrock, as shown in Fig. 1. An important factor contributing to the liquefaction of the deposits is the action of pore fluid pressure applied to the soil of the porous material. The existence of subsurface pore fluid flow generated temporarily during rainfall has been revealed in various studies (Barling et al. 1994; Hammermeister et al. 1982a, 1982b; Lowery et al. 1982; Scanlon et al. 2000), and the importance of this flow has been emphasized in various reports (Hewlett and Hibbert 1965; Weyman 1973; Whipkey 1965). The formation of a subsurface flow layer has been interpreted as flow within soils located over soils with low permeability, flow caused by large pores formed by the influence of organisms or vegetation roots around the ground surface, or a combination of these complex behaviors (Scanlon et al. 2000).

The presence of the fluid enhances the mobility of the solid phase through a variety of effects, including a reduction in shear strength of the granular phase (McArdell et al. 2007). Increasing fluid content in these flows tends to decrease their yield strength. Moreover, with increasing fluid content and progressively fewer particle interactions, debris flow transitions to grain flow and fluidized sediment flow. The sediment in grain flow is supported by the dispersive pressure arising from grainto-grain interactions and that in sediment flow is supported by upward-escaping pore fluid (Covault 2011). The interactions between the porous soil material and the interstitial fluid are central to understanding the dynamics of debris flow (Hutter et al. 1996; Iverson 1997). Large-scale laboratory experiments (Iverson 1997; Iverson and Vallance 2001; Major and Iverson 1999) strongly support that pore fluid pressures larger than hydrostatic values contribute to a reduction of the strength of the flowing material, thereby resulting in the commonly long run-out distances of debris flows.

\section{Vane-type rheometer considering upward flows}

\section{Measurement of rheological properties}

Rheology is a field of study directed toward understanding the characteristics and deformation of flowable materials, and a rheometer is a device for measuring the rheological properties of these 
materials. The rheological properties of flowable materials are represented by the yield stress and the viscosity of the material. Generally, the rheometer is used for measuring the viscosity of materials used in architecture, such as asphalt or cement, and the chemistry of paints and inks; rheometers are also used in food technology. The measurement methods can be divided into rotational viscometer and capillary viscometer types. When using a rotational viscometer, fluid is sheared at a nearly constant rate between a stationary and a rotating cylinder. Shear stress is obtained from the torque measured on the stationary cylinder. The rheological properties, such as yield stress and viscosity, are calculated from the relationship between shear stress and shear rate.

Over the last few decades, various rheometer tests have been developed to determine rheological properties, such as the yield stress and viscosity of a fluid material. For the determination of flow curves of sediment-water mixtures, large-scale devices have been adapted from standard rheometers, such as by Phillips and Davies (1991), Major and Pierson (1992), Coussot and Piau (1995), and Wallevik and Gjorv (1990). In several cases, the inner cylinder of a concentric cylinder system has been replaced with rotating blades (Banfill 1994; Tattersall and Bloomer 1979) or impellers (Tattersall and Banfill 1983; Wallevik and Gjorv 1990). Other researchers have used a large capillary (Schulze et al. 1991), inclined plane, or channel geometries for the determination of flow curve parameters (Coussot and Boyer 1995; Parsons et al. 2001; Whipple 1997). Most studies have focused on the development of equipment, such as a large geometry of the rheometer.

\section{Vane-type rheometer considering upward flow}

This study developed a vane-type rheometer subjected to upward flows to investigate the rheological properties of debris flow considering the initial condition of debris flow mobilization. This device can measure the rheological properties at an initiation state of debris flow in which a prescribed pore fluid pressure is applied to a porous material. This pore fluid pressure is an important factor in the generation of a debris flow and its flow-related behaviors. Fig. 2 shows a conceptual diagram of a vane-type rheometer considering upward flow. The vane-type rheometer considering 
upward flow is largely divided into three units: a measurement unit, a control unit, and a water flow control unit. The measurement part is composed of a cylindrical container, a four-way type vane, a torque sensor, and a motor. The torque value from the torque sensor is read at a specified time interval as the vane is rotated by the motor. The control unit consists of an RPM control device and a computer, which stores and displays the data. Vane rotation speed is adjusted by the rotation speed control device and, during an experiment, the computer stores torque values and rotation speed data in real time. Using the torque and RPM values obtained at each rotation speed, it is possible to calculate shear rate and shear stress.

Additionally, in this rheometer, a prescribed hydraulic gradient can be applied to a specimen with constant infiltration pressure. The constant hydraulic gradient is applied to the bottom of the container. The water flow control unit consists of a large water tank, a water supply tank with a moveable device, and a supply tube. The water supply tank provides a constant hydraulic gradient to the bottom of the container through the supply tube (i.e., water level difference is kept constant during the experiment). The hydraulic gradient is defined as the ratio of the water level difference $(\Delta h)$ to the sample's length $(L)$. To obtain a desired hydraulic gradient, the position of the water supply tank can be changed using a moveable device. A filter and a perforated board, which allow water to pass through but prevent soil with fine particles from passing through, are installed in the bottom of the container. The sand remains in the container during the experiment. It is assumed that the hydraulic gradient is constant through the sand because of homogeneous sand deposit.

By applying upward seepage to the bottom of the soil sample during a test, the rheological properties of the sample can be measured under the condition of upward infiltration of pore water in the sample. This experiment, by considering various seepage pressures with various hydraulic gradients in the sample, makes it possible to estimate rheological properties depending on the change of pore fluid pressure in soil particles. The rheological properties at debris flow initiation, at which liquefaction of loose deposits occurs, can be measured exactly using the vane-type rheometer. The estimated rheological properties of debris flow, which reflect hydraulic-mechanical properties, correspond to the initial properties of debris flow occurrence. 
In this study, the diameter $\left(D_{v}\right)$ and the height $\left(H_{v}\right)$ of the vane were $127 \mathrm{~mm}$, as shown in Fig. 3. The diameter of the container was $286 \mathrm{~mm}$. The vertical distance $\left(Z_{1}\right)$ from the top of the blade to the surface of the sample was $127 \mathrm{~mm}$, and the vertical distance $\left(Z_{2}\right)$ from the bottom of the blade to the floor of the container was 0.5 times the vane diameter $\left(D_{v}\right)$. Vertical bars were installed on the inside wall of the container to prevent slippage between the container inner wall and the sample and to induce artificially shear between the sample in the container at vane rotation.

\section{Characteristics of flow curve}

In general, the rheological properties of the fluid material are determined by analysis of the flow curve. As shown in Fig. 4, flow curves generally may have five different forms. The rheological properties obtained through experiments are utilized to back-analyze the phenomenological characteristics of debris flow. The rheological models often applied to debris flow analysis are the Bingham model and the Herschel-Bulkley model (Jeong, 2011; Malet et al. 2003); in this study, rheological properties such as yield stress and viscosity of the flow material were determined based on these two models. The Bingham model is defined by equation (1).

$$
\tau=\tau_{c-B}+\eta \dot{\gamma}
$$

where $\tau$ is shear stress, $\tau_{c-B}$ is Bingham yield stress, $\eta$ is viscosity, and $\dot{\gamma}$ is shear rate. The results obtained through the experiment can be expressed as the relationship between shear rate and shear stress, as shown in Fig. 4(a). In this case, the y-axis intercept value is defined as a Bingham yield stress, and the slope is defined as a viscosity.

The Herschel-Bulkley model, which is an extended form of the power law model obtained by adding the yield stress term, is defined by equation (2): 


$$
\tau=\tau_{c-H B}+K \gamma^{n}
$$

where $\tau_{c-H B}$ is Herschel-Bulkley model yield stress, $K$ is a flow parameter, and $n$ is a nondimensional flow index. The characteristics of flow curve behavior are differently described by the non-dimensional flow index $(n)$. For example, if $n<1$, the fluid has shear thinning behavior; and if $n>1$, the fluid shows shear thickening behavior, as shown in Fig 4(b).

\section{Experimental method}

Fig. 5 shows the particle size distribution curve of the sand used in this study. The uniformity coefficient of the sand was 1.8 and the coefficient of gradation was 1.1 , which indicates that the sand used in this study was composed of similar sizes. The soil was classified as poorly graded sand (SP), according to the Unified Soil Classification System (USCS). The maximum and minimum dry unit weights of the sand were $1.4 \mathrm{t} / \mathrm{m}^{3}$ and $2.0 \mathrm{t} / \mathrm{m}^{3}$, respectively.

To investigate the rheological properties of loose sands considering upward flow characteristics, this study conducted five series of experimental tests by increasing the hydraulic gradient from 0 to 2.0 with an interval of 0.5 . For the preparation of homogeneous loose samples, each sample was prepared by using free falling sand grains in water. The relative density of the saturated sand samples composed was about $40 \%$. The relative density was measured by using the weight of the sand and the container volume. Through several experimental tests, it was confirmed that the relative densities of the prepared sand samples were maintained at about $40 \%$.

Fig. 6 shows the experimental procedures of the rheometer tests considering upward flow. The experiment procedures were conducted in the order of sample composition, temperature check, hydraulic gradient application, vane intrusion, and vane rotation. Fig. 6(a) shows the sample composition and temperature check. Each experimental test was carried out under the same temperature condition of about $15^{\circ} \mathrm{C}$ (room temperature). As shown in Fig. 6(b), in the stage of 
hydraulic gradient application, the assigned value of hydraulic gradient, to have a uniform upward flow of water in the sample, was applied by adjusting the water height of the water supply tank of the flow control unit. Water infiltrates from the bottom of the container into the specimen. The constant hydraulic gradient was maintained during the test so that steady state condition was considered. The vane is penetrated into the sample as shown in Fig. 6(c). After penetration into the sample, the vane rotates with a designed rotational speed. The torque sensor in the measurement unit measures the torque values of the corresponding rotational speeds, as shown in Fig. 6(d). When a series of the process was finished using an assigned hydraulic gradient, the soil sample was recomposed within the container to have the same condition of relative density. The above process, Fig. 6(a-d), was then repeated under the same conditions, except for a different hydraulic gradient.

Each experiment included an increasing stage and a decreasing stage of RPM speed. The rotational speed of the vane ranged from about 5-100 rpm. During the experiment, the shear rate increased gradually from the minimum value to the maximum value of each test, and when the maximum value was reached, the shear rate decreased from the maximum value to the minimum value in reverse order. The curve obtained through this process is called a stress hysteresis loop. The RPM speed was divided into an increasing stage and a decreasing stage, as shown in Fig. 7. The experiment was conducted by classifying the rotation speed into a total of 15 steps. A constant RPM speed for each step was maintained for $\sim 20 \mathrm{~s}$, and the total time consumed by one experiment was approximately $5 \mathrm{~min}$.

Fig. 7 shows the RPM changes with time obtained from a total of five experiments with varying hydraulic gradient. The figure indicates that an almost constant RPM value was maintained for each step. The flow curve was generated by using the rotation speed and the torque value of vane measurement in each stage.

\section{Results and discussion}

\section{Relationship between shear stress and shear rate}


Fig. 8 shows a series of flow curves for the loose sand specimens with different hydraulic gradients (i.e., $\mathrm{i}=0.0-2.0$ ). The flow curves obtained in the experiments show a generally linear relationship between the shear stress and the shear rate, with both an increasing RPM stage and a decreasing RPM stage. The results of two experiments using the same conditions showed almost similar flow curves. This indicates that, through repetition, the test results were consistent. It also shows that no hysteresis behavior in the flow curves was observed in both the increasing stage and the decreasing stage for loose sand with a given hydraulic gradient. The viscosity of thixotropic materials does not follow the same path on structural breakdown and recovery. In most cases, when the shear rate is slowed, the stress path lags forming a hysteresis loop, which then returns to a point lower than the initial critical shear stress. The area within the hysteresis loop represents the energy consumed in structural breakdown. In this study, the hysteresis behavior was not observed becasue the loose sand may not be a thixotropic material.

In general, the rheological properties of silty soil are expressed as a shear thickening or as Bingham behavior (Jeong, 2011). However, according to studies by Coussot and Piau (1994), Locat (1997), and Jeong (2011), fine-grained soil containing a large amount of clay shows shear thinning behavior. Fine-grained soil containing abundant silt components shows a behavior experimentally close to Bingham behavior (Jeong 2011). For the loose sands used here, shear thickening behavior like the Herschel-Bulkley model was observed when the hydraulic gradient was 0 or 0.5 , as shown in Fig. 8(a) and (b). As the hydraulic gradient was increased to values greater than 1, the behavior changed to Bingham behavior, as shown in Fig. 8(c-e). Based on the test results, the flow curves of the loose sand specimens show forms such that shear thickening behavior dominates at low hydraulic gradient and Bingham behavior appears at high hydraulic gradient. The experiment test results show that the behavior of the flow curves for loose sands depend on the hydraulic gradient.

According to Barnes (1999), the characteristics of rheological properties can be defined easily by investigation of the relationship between viscosity and shear rate. Fig. 9 presents the flow curves for the loose soils in a semi-logarithmic plot of effective viscosity and shear rate. As the figure shows, shear thickening behavior was exhibited as the hydraulic gradient rate was increased from 0 to 0.5 . 
When the hydraulic gradient was increased to values greater than 1, the relationship between effective viscosity and shear rate showed straight Bingham behavior with almost similar effective viscosity values. The figure shows a clear difference in the relationship between effective viscosity and shear rate depending on hydraulic gradient. The effective viscosity increment with increase in hydraulic gradients is significant, especially in low shear rate range: e.g., the effective viscosity with $i=2.0$ increases almost 10 times than that with $i=0.0$. In fact, the effective viscosity of loose sands subjected to $i=2.0$ is almost constant during shearing. It means that this is close to Bingham behavior when the soil samples are subjected to high pore water pressure; thus it may result in a high mobilization of fluidized state of soils. Particularly, at low shear rate, there is scatter in effective viscosity values. This phenomenon may be resulted from a very low rotation speed of the vane, which provides unstable measured values of torque. However, as shear rate increases, the viscosities of the tested loose sand show a tendency to converge to a certain value.

\section{Flow curve of loose sands}

Fig. 10 shows the results of the experimental tests in which the loose sand was subjected to prescribed hydraulic gradients as applied to the rheological models. The test results show that the flow curves of the loose sand represent a mixed form of Bingham behavior and shear thickening behavior, depending on the applied hydraulic gradient. In this study, the Bingham model and the HerschelBulkley model were used to express the shear behaviors of the soil for analysis of the flow curves. Jeong (2011) reported that the Bingham and Herschel-Bulkley models are appropriate for investigating the characteristics of the flow behaviors of silty soil and can be utilized for evaluating the fluidity of debris flow (Jeong et al. 2010; Locat 1997; Malet et al. 2003). Fig. 10(a) shows the results of a fitting analysis applying the Bingham model, and Fig. 10(b) shows the relationship between shear rate and shear stress obtained by applying the Herschel-Bulkley model. The rheological parameters obtained from the Bingham and Herschel-Bulkley models are summarized in Table 1 . The values in Table 1 shows average values. Both the Bingham model and the Herschel- 
Bulkley model well represent the flow curves of the loose sand obtained from the experimental test results and have a high goodness of fit. The value of $\mathrm{R}^{2}$ is higher than 0.85 .

Fig. 10 indicates that the relationship between shear stress and shear rate depends on the hydraulic gradient. At a given shear rate, the shear stress of the flow materials decreases as the hydraulic gradient increases. This means that the pore fluid pressure that acts within the loose sand samples depending on hydraulic gradient is a factor that can reduce the shear stress of fluid materials. Upward seepage of water influences the rheological properties of debris flow, which contribute to various characteristics of debris flow including velocity, run-out distance, and depositional area.

\section{Rheological characteristics of loose sands subjected to upward flow}

The rheological parameters commonly used for mobility assessment of debris flow are yield stress and viscosity. Fig. 11 shows variations of yield stress with changing hydraulic gradient. The yield stresses of the tested materials were calculated by the Bingham and Herschel-Bulkley models. The yield stress obtained by using the Herschel-Bulkley model was slightly higher than that from the Bingham model. Overall, yield stress shows a tendency of decreasing linearly as hydraulic gradient increases. The value of yield stress with a hydraulic gradient of 0 is about 1.5 times greater than the value when a hydraulic gradient of 2.0 is applied. Fig. 11 clearly shows that the pore fluid pressure resulting from upward flow in the soil sample affects the yield stress of the sample.

Fig. 12 shows the Bingham plastic viscosity values calculated by the Bingham model as hydraulic gradient change from 0 to 2.0. Unlike the relationship between yield stress and hydraulic gradient shown in Fig. 11, the values of Bingham plastic viscosity remain almost constant, irrespective of hydraulic gradient, and scatter mostly within 30-35 Pa.s. According to Bingham model, yield stress decreases with decrease in effective stress (i.e., with increase in hydraulic gradient) and viscosity is independent of effective stress. It is noted that after the critical hydraulic gradient is reached, yield stress continues to decrease due to upward seepage pressure induced from water flows. These results are also consistent with the constitutive behaviors of dense suspensions with friction law (Rognon et 
al. 2011).

\section{Discussion}

It is well known that yield stress and viscosity are key parameters affecting the mobility of debris flows and that they also influence the shape of the deposit (Locat et al. 2004). Therefore, it is very important to determine the yield stress and viscosity of debris flow materials considering the generation of pore fluid pressure in soil during the process of natural slope failure. This makes it possible to predict accurately the flow characteristics and sediment characteristics of debris flow, such as the affected area, speed, and impact pressure. In this study, the pore fluid pressure acting in the porous materials was found to influence the rheological properties of debris flow. This study was able to obtain rheological properties much closer to those of the real phenomenon by implementing upward flow during the initiation of debris flow using an experimental method.

The rheological properties of fluid materials at initiation of debris flow - or in other words, the rheological properties at the liquefied condition - can be calculated by using basic soil mechanics such as upward seepage pressure and effective stress. In the case of water flowing upward within a soil sample, the pore water pressure is increased and the effective stress is decreased compared to the case in which water does not flow. The reduction in effective stress is caused by upward seepage pressure. The hydraulic gradient at which the effective stress becomes 0 is defined as the critical hydraulic gradient, which is expressed by equation (3):

$$
i_{c}=\frac{\gamma^{\prime}}{\gamma_{w}}=\frac{\frac{G_{s}-1}{1+e} \gamma_{w}}{\gamma_{w}}=\frac{G_{s}-1}{1+e}
$$

where $\gamma^{\prime}$ is submerged unit weight, $\gamma_{w}$ is unit weight of water, $G_{s}$ is specific gravity, and $e$ is the void ratio. The critical hydraulic gradient is known to be generally within $0.9-1.1$. If the hydraulic 
gradient applied to a soil is larger than the critical hydraulic gradient, liquefaction occurs within the soil. Based on this theory, this study was able to estimate the rheological properties of loose sand samples at the liquefied condition so that the measured rheological properties depended on hydraulic gradient. For example, if the critical hydraulic gradient of a sample is 1, the yield stress and viscosity can be estimated as 1,154.7 $\mathrm{Pa}$ and $32.5 \mathrm{~Pa} \cdot \mathrm{s}$, respectively, at the liquefied condition of the loose sand, as shown in Figs. 11 and 12, respectively.

As a result, it was possible to simulate the field behavior of debris flow events using the estimated rheological properties under the condition of liquefaction (i.e., critical hydraulic gradient). The results of this study can be applied for small particle mixtures like sand grains. A debris flow includes two phases: solid phase and liquid phase (Pudasaini 2012). The results of this study can be applied to the liquid phase of debris flow. The solid phase belongs to the large size particles $(>2 \mathrm{~mm})$. We need more researches to evaluate characteristics of interaction between solid phase and liquid phase.

\section{Conclusions}

This study proposed a measuring device for investigating the rheological properties of soil subjected to upward flow and analyzed the rheological properties of a loose sand sample at different hydraulic gradients. As a result, it was possible to analyze the rheological properties at the condition of liquefaction and initiation of debris flow. This makes it possible to simulate accurately the mobility of debris flow. The following conclusions were drawn from the experimental test results.

- No hysteresis behaviors of flow curves were observed in either an increasing RPM stage or a decreasing RPM stage for the loose sand.

- Flow curves of the loose sand specimens showed a form in which shear thickening behavior dominates at low hydraulic gradient but Bingham behavior appears at high hydraulic gradient. The experimental test results showed that the behaviors of flow curves for loose sand depend on hydraulic gradient.

- The flow behaviors of loose sand in the shear stress and shear rate relationship depend on 
hydraulic gradient. The shear stress of loose sand decreases as the hydraulic gradient increases.

- The yield stress obtained from the Herschel-Bulkley model was slightly higher than that from the Bingham model. The yield stress decreased linearly as the hydraulic gradient increased. However, the Bingham plastic viscosity maintained a constant value irrespective of changes of hydraulic gradient. This indicates that pore fluid pressure within loose sand samples is a key factor reducing the shear stress of fluid materials.

\section{Acknowledgments}

This research was supported by the Public Welfare and Safety Research Program through the National Research Foundation of Korea, funded by the Ministry of Science, ICT, and Future Planning (grant No. 2012M3A2A1050977), a grant (13SCIPS04) from Smart Civil Infrastructure Research Program funded by Ministry of Land, Infrastructure and Transport of Korea government and Korea Agency for Infrastructure Technology Advancement and the Brain Korea 21 Plus. 


\section{References}

Barling, R. D., Moore, I. D., and Grayson, R. B. 1994. A quasi-dynamic wetness index for characterizing the spatial distribution of zones of surface saturation and soil water content Water Resour, Res., 30, pp. 10291044.

Barnes, H. A. 1999. The yield stress - a review or ' $\pi \alpha v \tau \alpha \rho \varepsilon l^{\prime}$-everything flows? Journal of Non-Newtonian Fluid Mechanics, 81 (1-2), pp. 133-178.

Barnes, H. A., Hutton, J. F. and Walters, K. 1989. An introduction to rheology, Elsevier Science Publishers, Amsterdam.

Banfill, P. F. G. 1994. Rheological methods for assessing the flow properties of mortar and related materials, Construction and Building Materials, Vol. 8, pp.43-50.

Coussot, P., and Piau, J. M. 1994. On the behavior of fine mud suspensions, Rheologica Acta, 33(3) pp. 175184.

Coussot, P., and Boyer, S. 1995. Determination of yield stress fluid behaviour from inclined plane test. Rheol Acta 34, pp. 534-543.

Coussot, P., and Piau, J. M. 1995. A large-scale field coaxial cylinder rheometer for the study of the rheology of natural coarse suspensions, Journal of Rheology 39, pp. 105-124.

Covault, J. A. 2011. Submarine fans and canyon-channel systems: A review of processes, products, and models, Nat. Educ. Knowl., 3(10), 4.

Gabet, E. J., and Mudd, S. M. 2006. The mobilization of debris flows from shallow landslides Geomorphology, 74, pp. 207-218.

Hammermeister, D. P., Kling, G. F., and Vomocil, J. A. 1982a. Perched water tables on hillsides in western Oregon, I, Some factors affecting their development and longevity. Soil Sci. Soc. Am. J., Vol. 46, No. 4, pp. $811-818$.

Hammermeister, D. P., Kling, G. F., and Vomocil, J. A. 1982b. Perched water tables on hillsides in western Oregon, II, Some factors affecting their development and longevity. Soil Sci. Soc. Am. J., Vol. 46, No. 4, pp. $819-826$.

Hutter, K., Svendsen, B., and Rickenmann, D. 1996. Debris flow modeling: A review, Continuum Mech. 
Thermodyn., 8, pp. 1-35.

Hewlett, J. D., and Hibbert, A. R. 1965. Factors affecting the response of small watersheds to precipitation in humid areas, paper presented at the International Symposium on Forest Hydrology. Pa. State Univ., University Park.

Ilstad, T., De Blasio, F.V., Elverhøi, A., Harbitz, C. B., Engvik, L., Longva, O., and Marr, J. G. 2004. On the frontal dynamics and morphology of submarine debris flows. Marine Geology 213, pp. 481-497.

Imran, J., Parker, G., Locat, J., and Lee, H. 2001. 1D numerical model of muddy subaqueous and subaerial debris flows, J. Hydr. Eng., Vol. 127, pp. 959-968.

Iverson, R. M., and Vallance, J. W. 2001. New views of granular mass flows, Geology, 29, pp. 115-118.

Iverson, R. M. 1997. The physics of debris flows, Rev. Geophys., 35, pp. 254-296.

Jeong, S. W., Locat, J., Leroueil, S., and Malet, J.-P. 2010. Rheological properties of fine-grained sediments: the roles of texture and mineralogy, Can. Geotech. J., 47, pp. 1011-1023.

Jeong, S. W. 2011. Rheological models for describing fine-laden debris flows: Grain-size Effect, Journal of Korean Geotechnical Society, Vol. 27, No. 6, pp. 49-61.

Kim, H. T., Kim, G. H., Lee, H. J., and Park, D. K. 2002. The Risk Analysis of Debris Flow Occurrence Using GIS, KSCE Conference, 2183-2186.

Lowery, B., Kling, G. F., and Vomocil, J. A. 1982. Overland flow from sloping land: Effects of perched water tables and sloping drains, Soil Sci. Soc. Am J., Vol. 46, No. 1, pp. 93-99.

Liddell P. V., and Boger D. V. 1996. Yield stress measurements with the vane, J. of Non-Newtonian Fluid Mechanics, 63, pp. 235.

Locat, J. 1997. Normalized rheological behaviour of fine muds and their flow properties in a pseudoplastic regime, In Debris-flow Hazards Mitigation: Mechanics, Prediction, and Assessment. Water Resources Engineering Division, American Society of Civil Engineers, New York. pp. 260-269.

Locat, J., Lee, H. J., Locat, P., and Imran, J. 2004. Numerical analysis of the mobility of the Palos Verdes Debris Avalanche, California, and its implication for the generation of tsunamis, Mar. Geol., Vol. 203, pp. $269-280$.

Locat, J., and Demers, D. 1988. Viscosity, yield stress, remoulded strength, and liquidity index relationships for sensitive clays, Can. Geotech. J., Vol. 25, pp. 709-806.

McArdell, B. W., Bartelt, P., and Kowaslski, J. 2007. Field observations of basal forces and fluid pore 
pressure in a debris flow. Geophys. Res. Lett., 34, L07406.

Major, J. J., and Pierson, T. C. 1992. Debris flow rheology: experimental analysis of fine-grained slurries, Water Resources Research, 28 pp. 841-857.

Major, J., and Iverson, R. M. 1999. Debris-flow deposition: Effects of pore-fluid pressure and friction concentrated at flow margins, Geol. Soc. Am. Bull., 110, pp. 1424-1434.

Malet, J. P., Remaître, A., Maquaire, O., Ancey, C., and Locat, J. 2003. Flow susceptibility of heterogeneous marly formations. Implications for torrent hazard control in the Barcelonnette basin (Alpes-de-HauteProvence, France), In Proceedings of the $3^{\text {rd }}$ International Conference on Debris-Flow Hazards Mitigation, Davos, Switzerland, 10-12 September, 2003. Edited by D. Rickenmann and C. L. Chen. Millpress, Rotterdam, the Netherlands. pp. 351-362.

Malet, J. -P., Laigle, D., Remaître, A., and Maquaire, O. 2005. Triggering conditions and mobility of debris flows associated to complex earthflows, Geomorphology, 66, pp. 215-235.

O’Brien, J. S., and Julien, P. Y. 1988. Laboratory analysis of mudflow properties," Journal of Hydraulic Engineering, Vol. 114, No. 8, pp. 877-887.

Pudasaini, S. P. 2012. A general two-phase debris flow model, Journal of Geophysical Research, 117, p. F03010 http://dx.doi.org/10.1029/2011JF002186

Phillips, C. J., and Davies, T. R. H. 1991. Determining rheological parameters of debris flow material, Geomorphology 4, pp. 101-110.

Parsons, J. D., Whipple, K. X., and Simioni, A. 2001. Experimental study of the grain-flow, fluid-mud transition in debris flows, Journal of Geology 109, pp. 427-447.

Rognon, P. G., Einav, I., and Gay, C. 2011. Flowing resistance and dilatancy of dense suspensions: lubrication and repulsion, J. Fluid Mech., 689, pp. 75-96.

Schatzmann, M., Fischer, P., and Bezzola, G. R. 2003. Rheological behavior of fine and large particle suspensions J Hydraul Eng-ASCE, 129 (10), pp. 796-803.

Scotto di Santolo, A., Pellegrino, A. M., and Evangelista, A. 2010. Experimental study on the rheological behaviour of debris flow, Nat. Hazards Earth Syst. Sci., 10, pp. 2507-2514

Scanlon, T. M., Raffensperger, J. P., and Hornverger, G. M. 2000. Shallow subsurface storm flow in a forested headwater catchment: Observations and modeling using a modified TOPMODEL, Water Resour. Res., Vol. 36, No. 9, pp. 2575-2586. 
Sassa, K. 2000. Mechanism of flows in granular soils (Invited paper). Proceedings of GeoEng2000, Melbourne, Vol. 1, pp. 1671- 1702 .

Schulze, B., Brauns, J., and Schwalm, I. 1991. Neuartiges Baustellen-Messgerät zur Bestimmung der Fliessgrenze von Suspensionen. Sonderdruck aus Geotechnik 3/1991. Heidelberger Zement, Berliner Strasse 6, D-6900 Heidelberg.

Tattersall, G. H., and Bloomer, S. J. 1979. Further development of the two-point test for workability and extension, Magazine of Concrete Research, 31, pp. 202-210.

Tattersall, G. H., and Banfill, P. F. G. 1983. The Rheology of Fresh Concrete, Pitman, London Barling et al. 1994.

Wang, G. H., and Sassa, K. 2003. Pore-pressure generation and movement of rainfall-induced landslides: effects of grain size and fine-particle content, Engineering Geology, 69, pp. 109-125.

Wang, G., Sassa, K. 2002. Post-failure mobility of saturated sands in undrained load-controlled ring shear tests, Canadian Geotechnical Journal, 39, pp. 821-837.

Wallevik, O. H., and Gjorv, O. E. 1990. Development of a coaxial cylinder viscometer for fresh concrete, In: Proceeding of the Rilem Colloquium. Chapman and Hall, Hanover, pp. 213-224.

Whipple K. X. 1997) Open-channel flow of Bingham fluids: Applications in debris flow research. J Geol 105, pp. 243-262.

Whipkey, R. Z. 1965. Subsurface storm flow from forested slopes, Bull. Int. Assoc. Sci. Hydrol., Vol. 10, pp. $74-85$.

Weyman, D. R. 1973. Measurements of the downslope flow of water in a soil, J. Hydrol., Vol. 20, pp. 267-288.

Winter, M.G., Macgregor, F., Shackman, L. 2005. Scottish Road Network Landslides Study, Scottish Executive. 


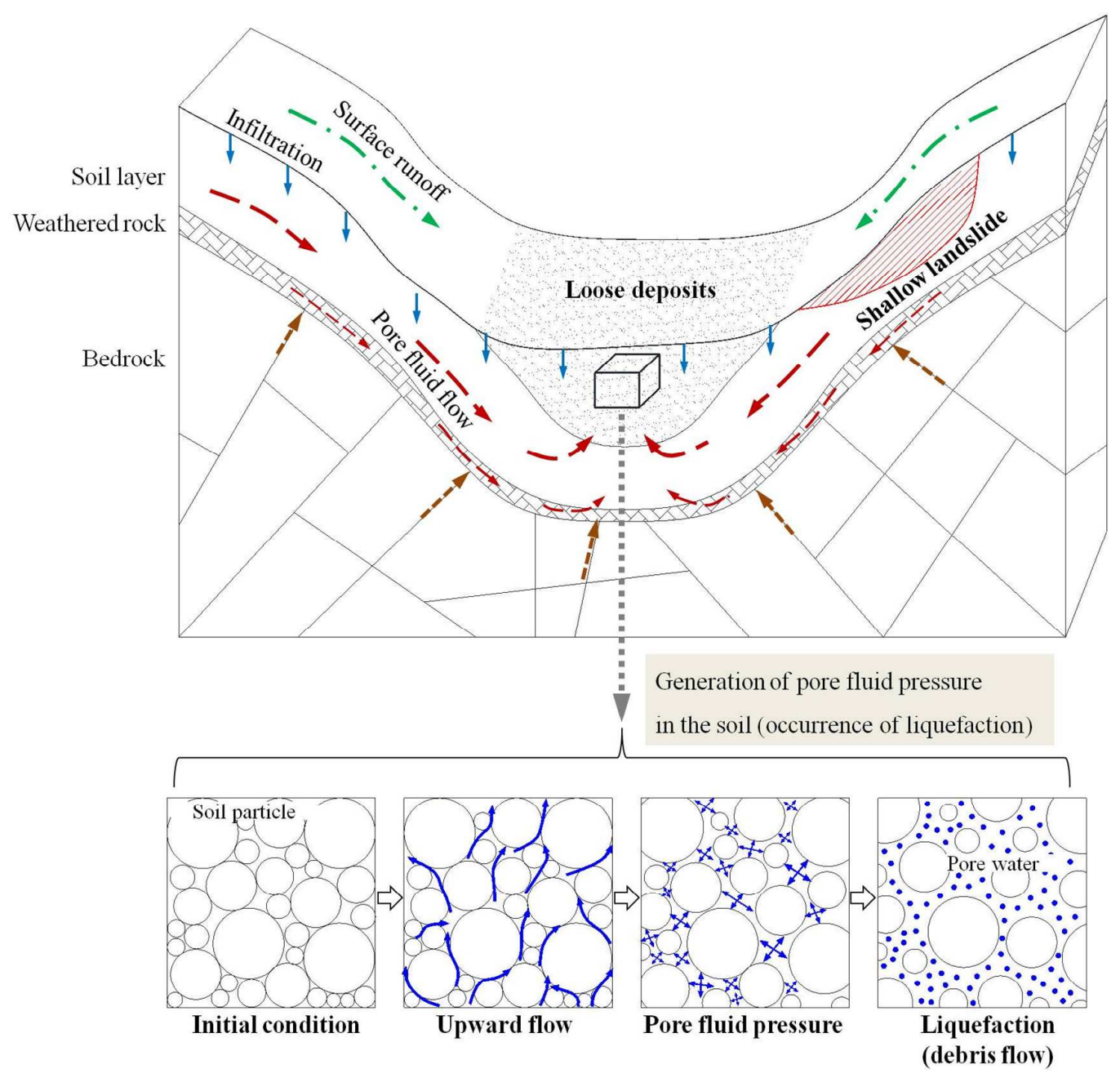

Fig. 1. Schematic diagram of debris flow mobilization. 


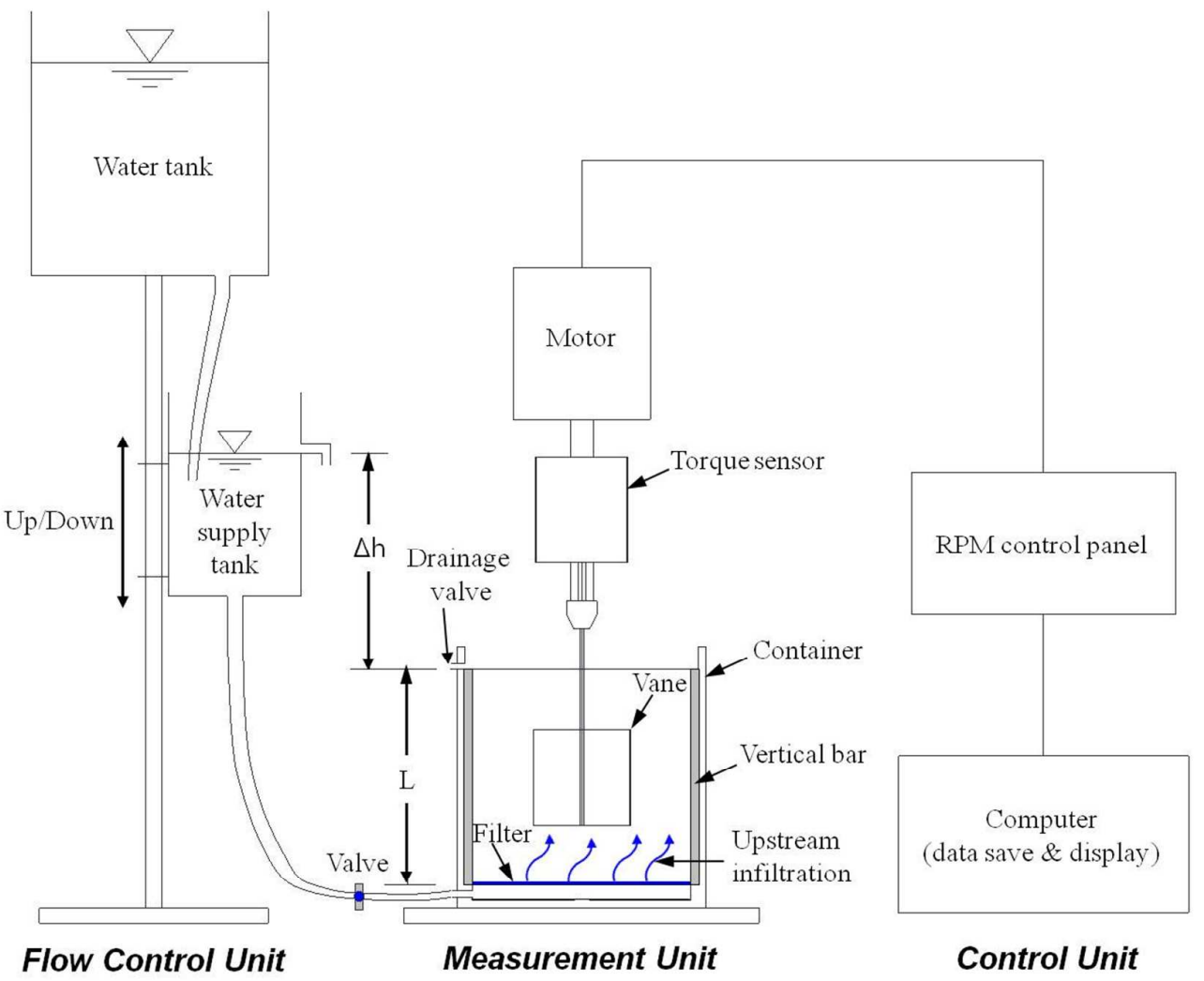

Fig. 2. Vane-type rheometer considering upward flow.

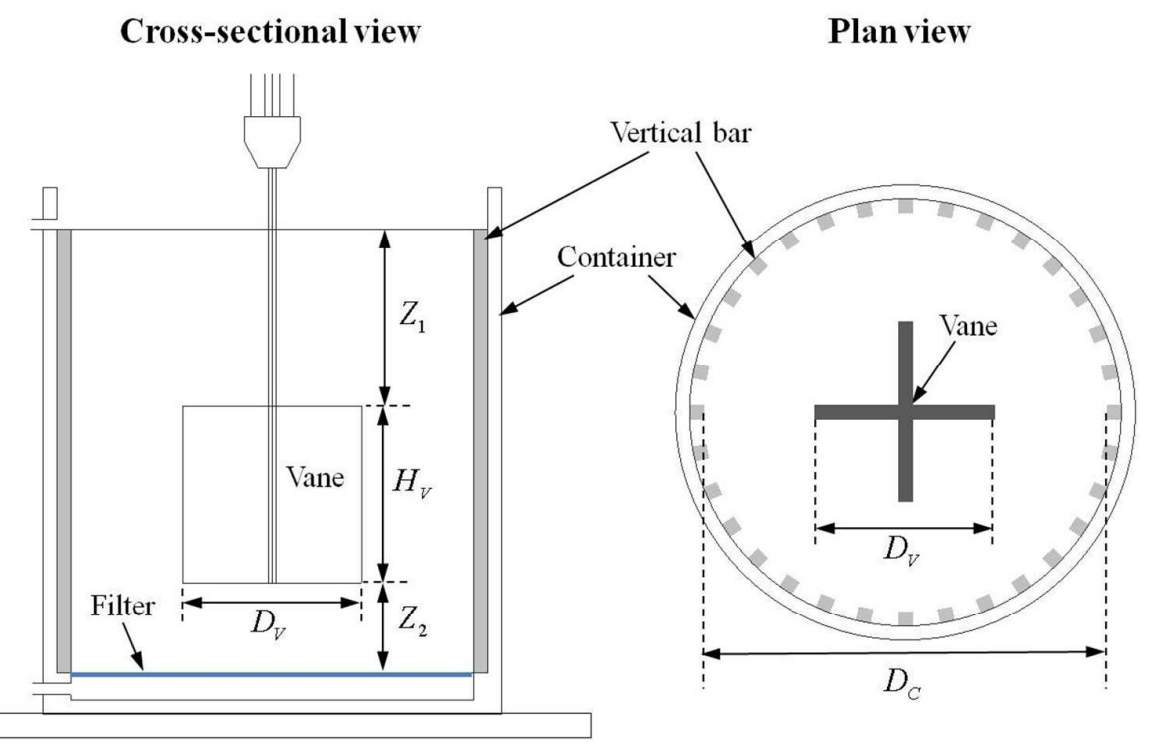

Fig. 3. Details of vane and container. 

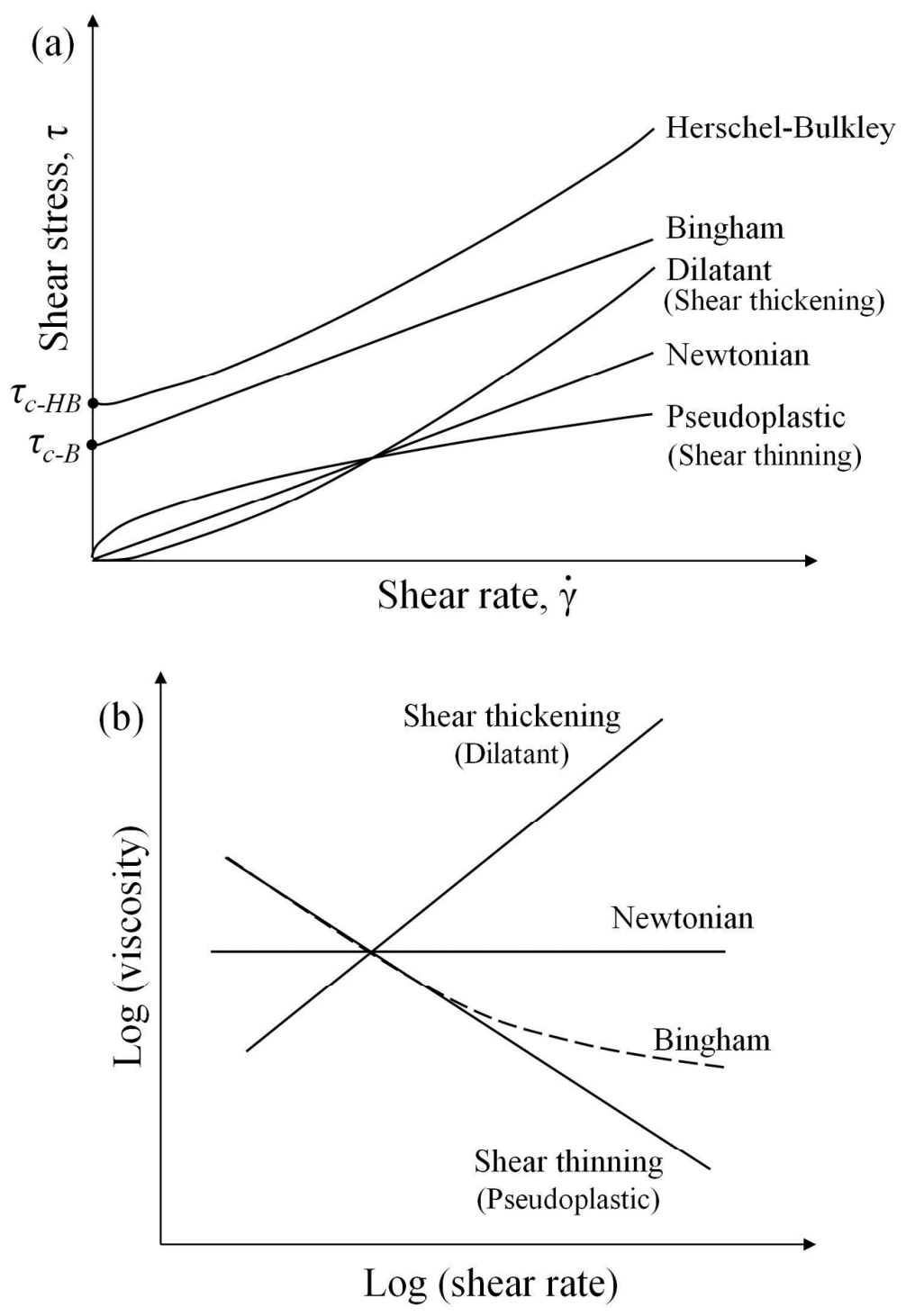

Fig. 4. Characteristics of the flow curve (Barnes et al., 1989): (a) Relationship between shear stress and shear rate; (b) Relationship between viscosity and shear rate. 


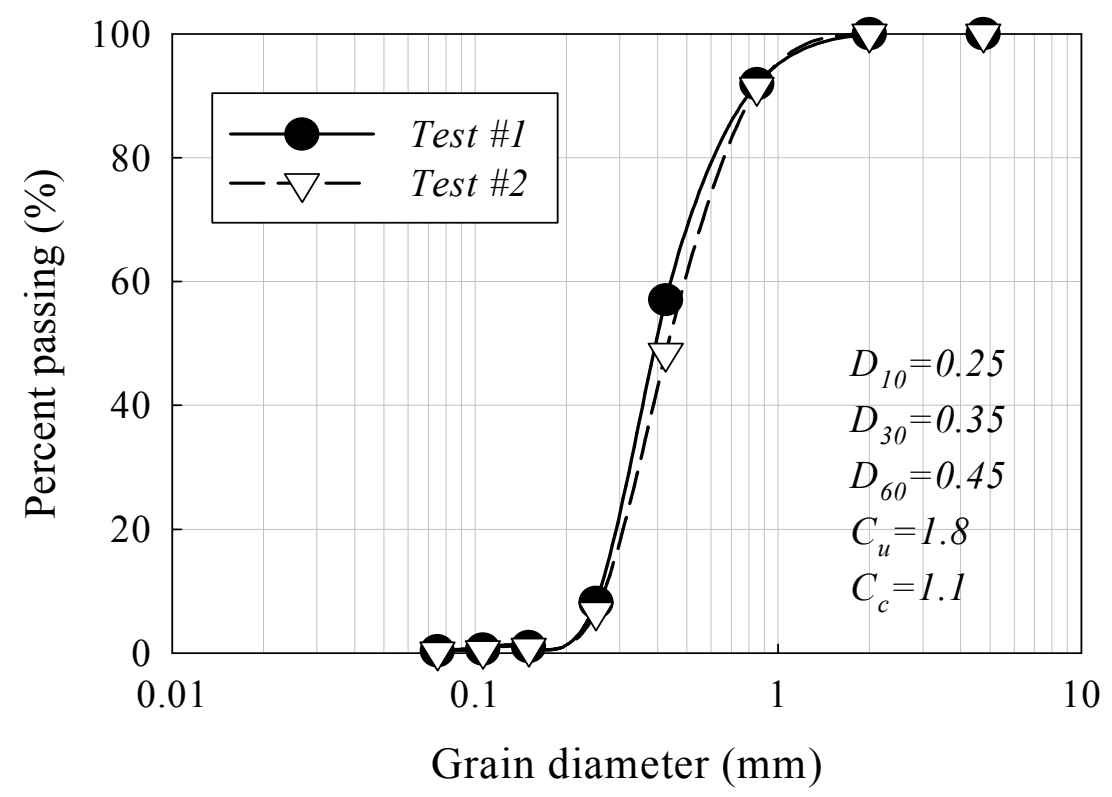

Fig. 5. Grain size distribution curves of the sand.

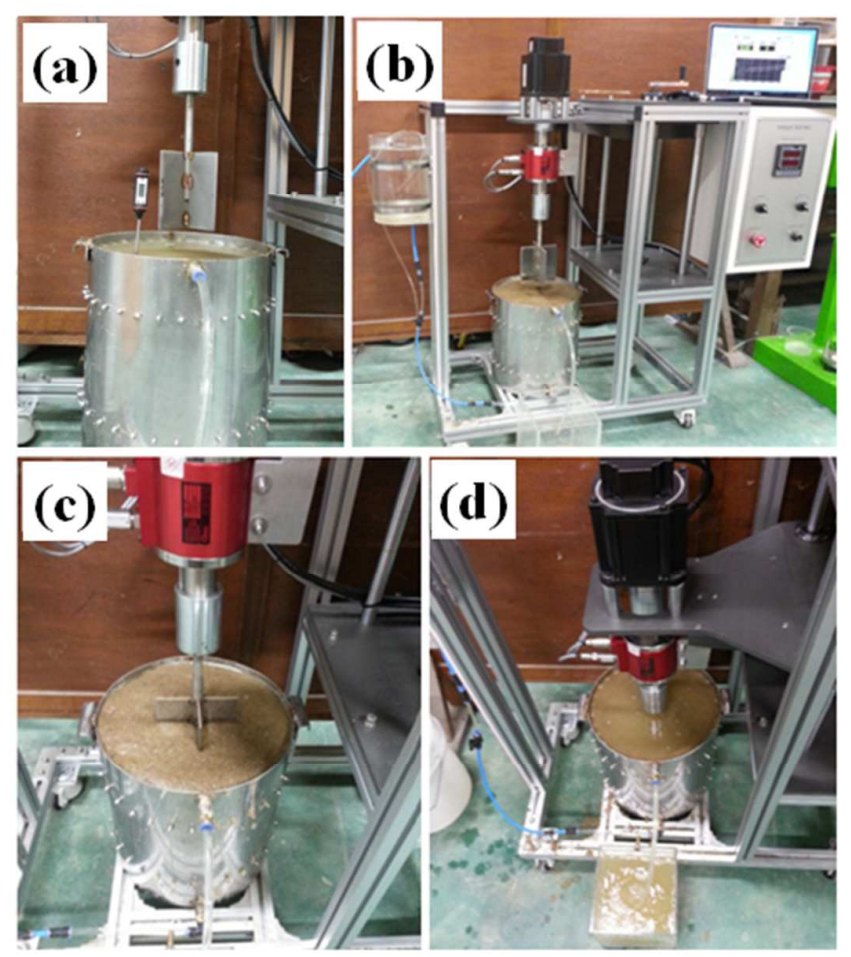

Fig. 6. Experimental procedure: (a) Sample composition and temperature check; (b) Hydraulic gradient applied; (c) Vane penetration; (d) Vane rotation. 


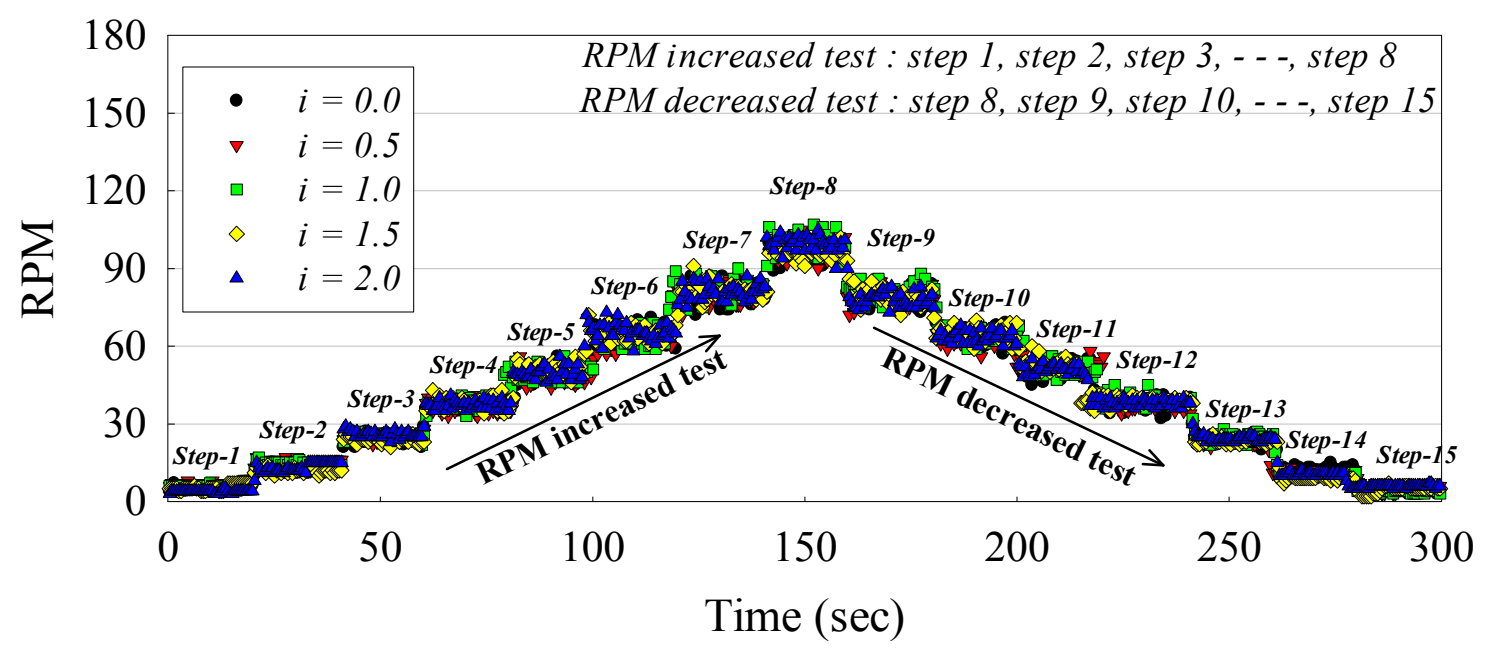

Fig. 7. Applied RPM with time. 

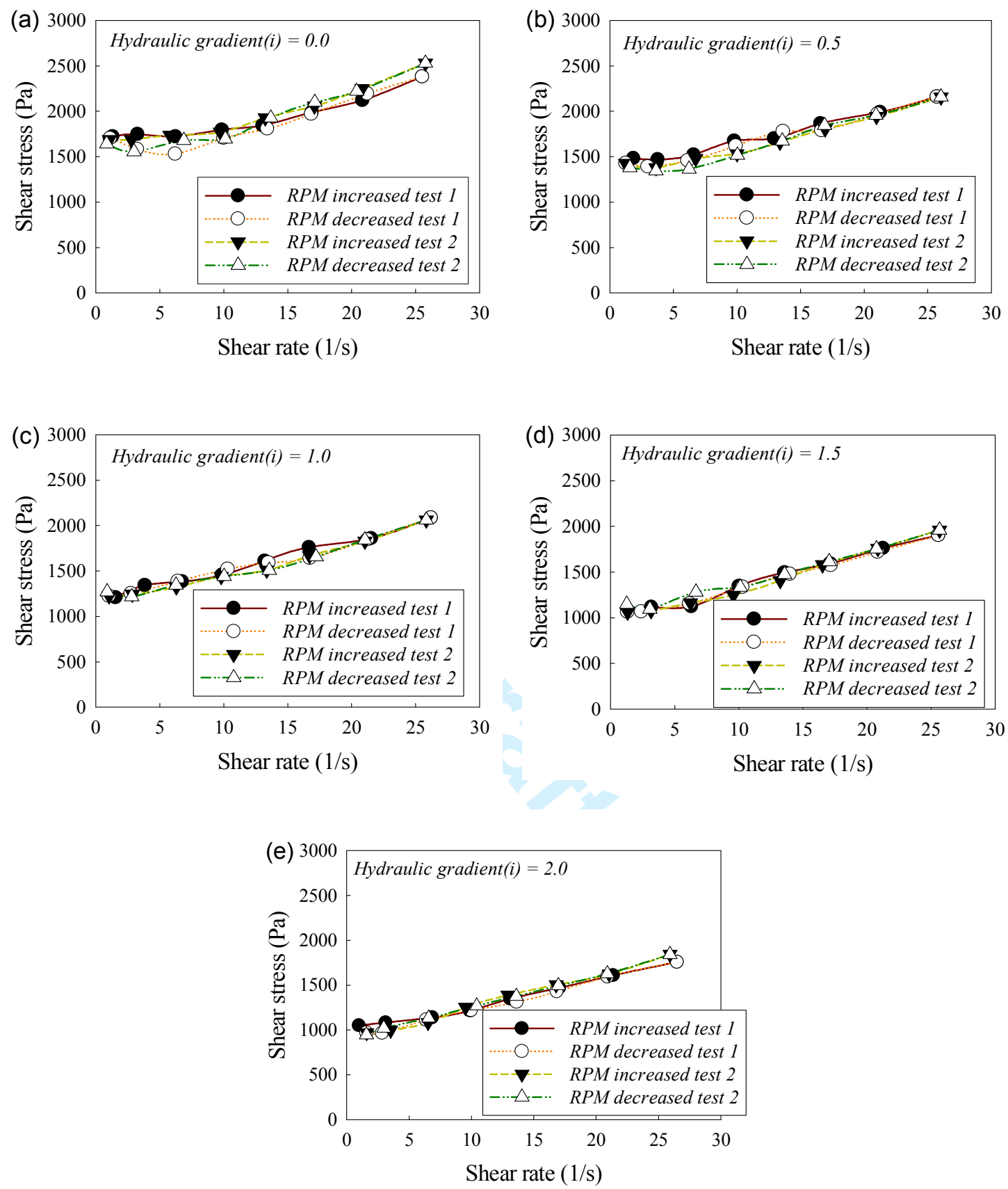

Fig. 8. Relationship between shear stress and shear rate at different hydraulic gradients: (a) Hydraulic gradient, $\mathrm{i}=0.0$; (b) Hydraulic gradient, $\mathrm{i}=0.5$; (c) Hydraulic gradient, $\mathrm{i}=1.0$; (d) Hydraulic gradient, $\mathrm{i}=1.5$; (e) Hydraulic gradient, $\mathrm{i}=2.0$. 


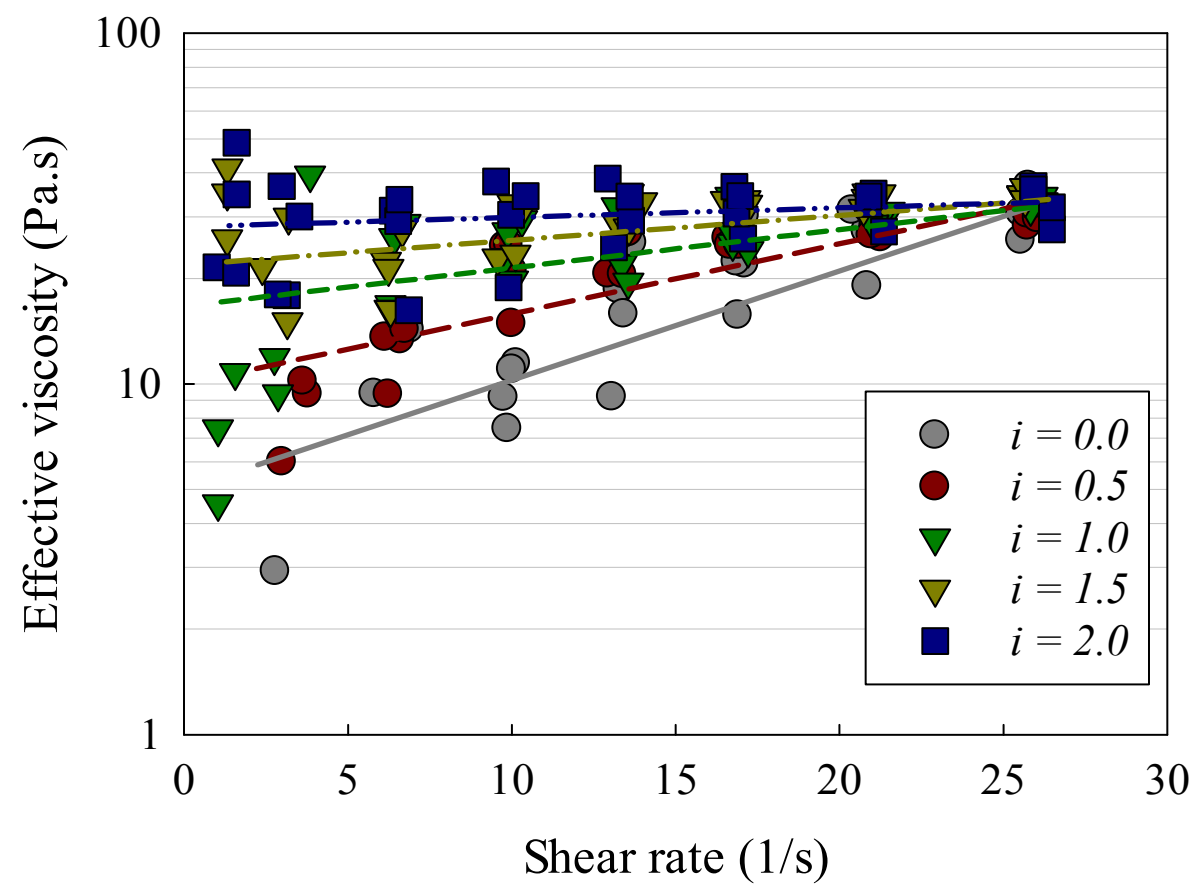

Fig. 9. Relationship between effective viscosity and shear rate at different hydraulic gradients. 

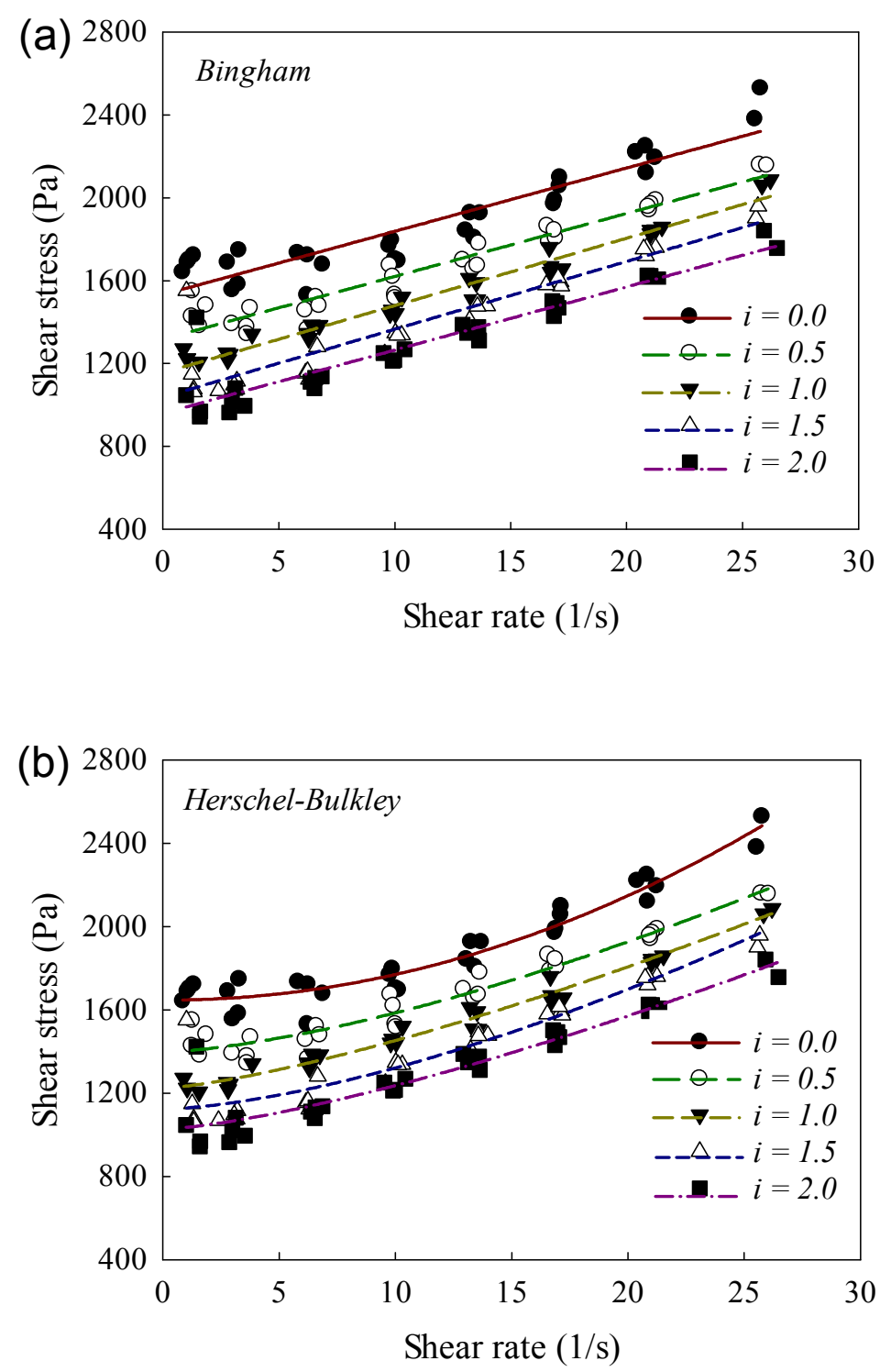

Fig. 10. Flow behavior of sand with variation of hydraulic gradient: (a) The results of fitting analysis using the Bingham model; (b) The results of fitting analysis using the Herschel-Bulkley model. 


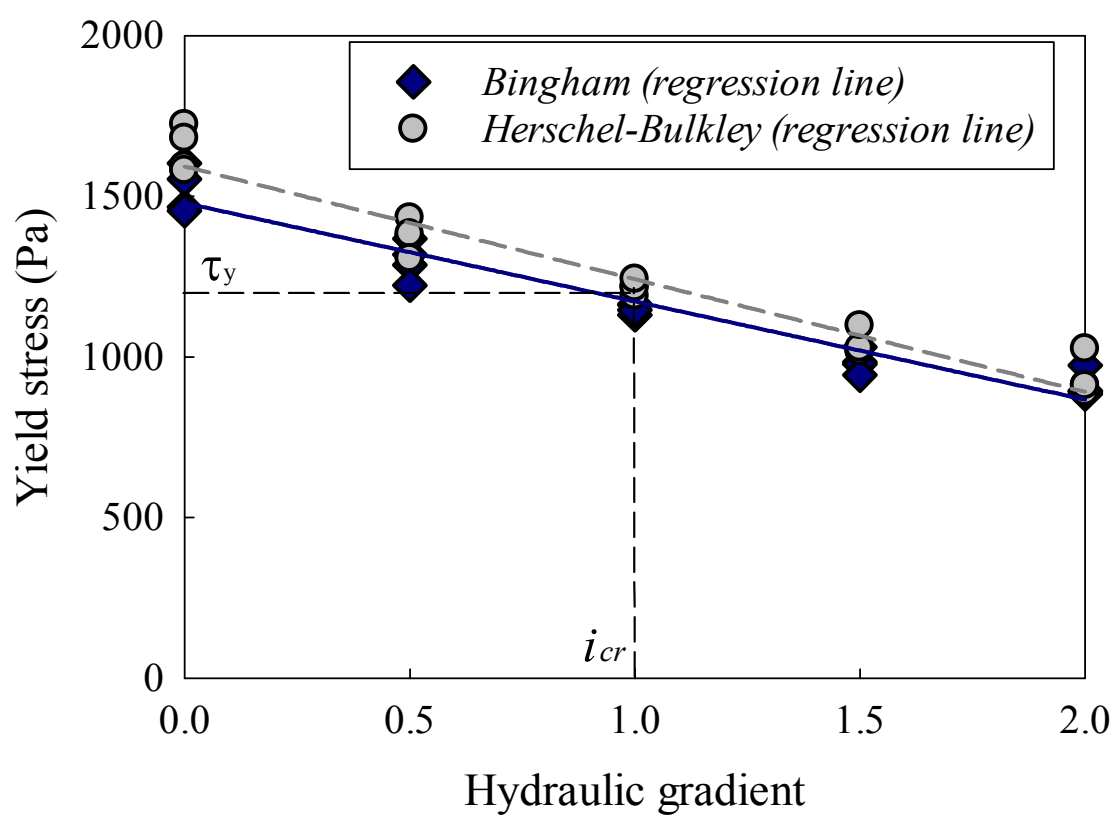

Fig. 11. Relationship between yield stress and hydraulic gradient.

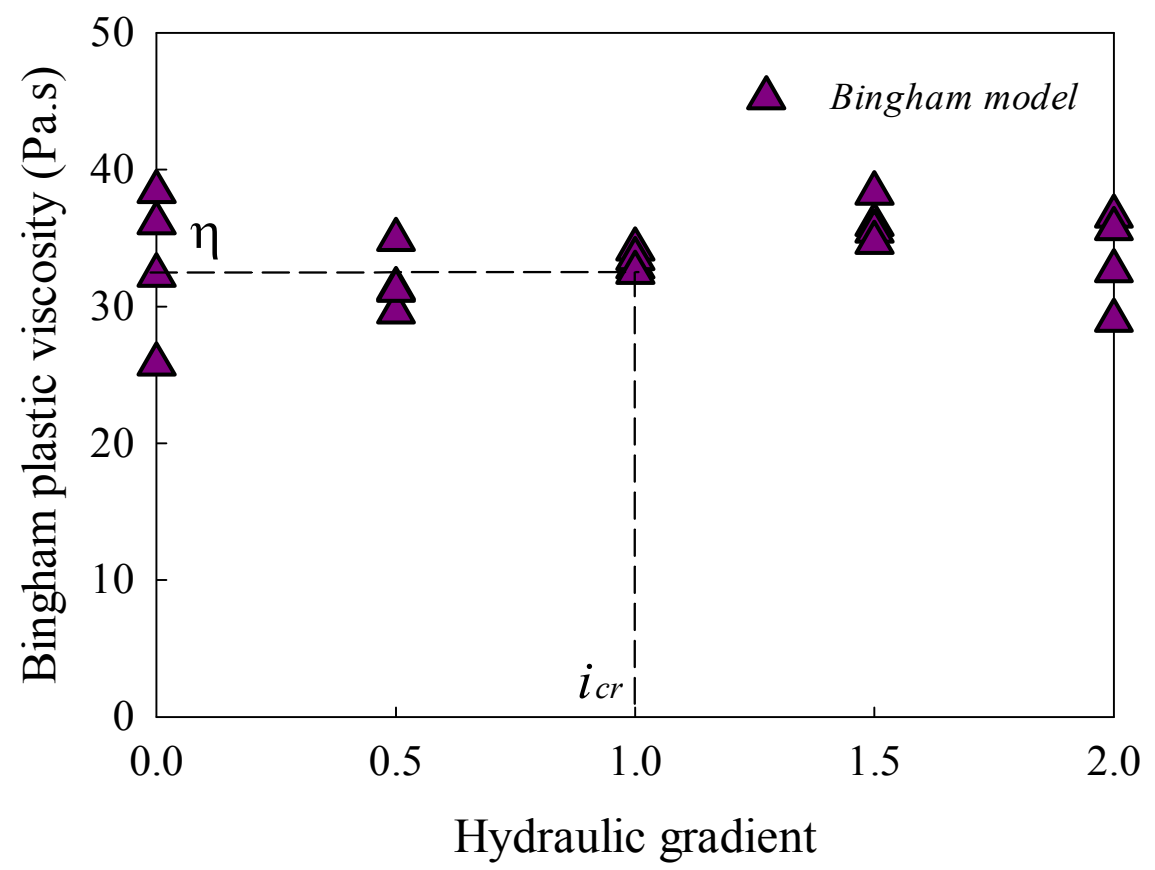

Fig. 12. Relationship between plastic viscosity and hydraulic gradient. 
Table 1. Rheological parameters of Bingham and Herschel-Bulkley models.

\begin{tabular}{c|c|c|c|c|c}
\hline \multirow{2}{*}{$\begin{array}{c}\text { Hydraulic } \\
\text { gradient } \\
(\Delta h / L)\end{array}$} & $\begin{array}{c}|c| \\
\tau_{c-B} \\
(\mathrm{~Pa})\end{array}$ & $\begin{array}{c}\eta \\
(\mathrm{Pa} . \mathrm{s})\end{array}$ & $\begin{array}{c}\tau_{c-H B} \\
(\mathrm{~Pa})\end{array}$ & $K$ & $n$ \\
\cline { 2 - 6 } & 1532.6 & 30.6 & 1646.9 & 1.17 & 2.02 \\
\hline 0.0 & 1316.8 & 30.4 & 1397.1 & 6.13 & 1.49 \\
\hline 0.5 & 1154.7 & 32.5 & 1223.1 & 10.29 & 1.35 \\
\hline 1.0 & 1037.4 & 32.8 & 1122.8 & 5.74 & 1.54 \\
\hline 1.5 & 959.6 & 30.5 & 1026.0 & 8.81 & 1.38 \\
\hline
\end{tabular}

